\title{
Extended characterization of the novel co-isogenic C57BL/6J Prnp/ mouse line
}

Nuvolone, Mario ; Sorce, Silvia ; Paolucci, Marta ; Aguzzi, Adriano

DOI: https://doi.org/10.1080/13506129.2017.1289913

Posted at the Zurich Open Repository and Archive, University of Zurich ZORA URL: https://doi.org/10.5167/uzh-137095

Journal Article

Accepted Version

Originally published at:

Nuvolone, Mario; Sorce, Silvia; Paolucci, Marta; Aguzzi, Adriano (2017). Extended characterization of the novel co-isogenic C57BL/6J Prnp/ mouse line. Amyloid, 24(Suppl 1):36-37.

DOI: https://doi.org/10.1080/13506129.2017.1289913 


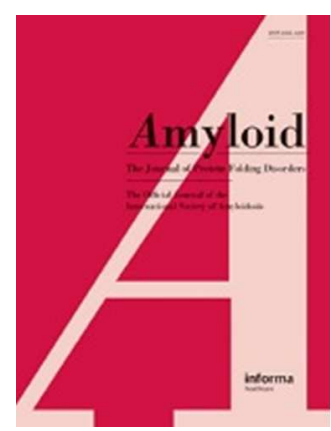

\section{Extended characterization of the novel co-isogenic C57BL/6J Prnp ${ }^{-/-}$mouse line}

\begin{tabular}{|r|l|}
\hline Journal: & Amyloid \\
\hline Manuscript ID & Draft \\
\hline Manuscript Type: & Letter to the Editor \\
\hline Date Submitted by the Author: & n/a \\
\hline Complete List of Authors: & $\begin{array}{l}\text { Nuvolone, Mario; Institute of Neuropathology - University Hospital Zurich, } \\
\text { Sorce, Silvia; Institute of Neuropathology - University Hospital Zurich } \\
\text { Paolucci, Marta; Institute of Neuropathology - University Hospital Zurich } \\
\text { Aguzzi, Adriano; Institute of Neuropathology - University Hospital Zurich }\end{array}$ \\
\hline Keywords: & Prion, Prion disease, Knockout, Mouse models, Genetic background \\
\hline \multicolumn{2}{|l}{} \\
\hline
\end{tabular}

SCHOLARONE $^{\text {m }}$

Manuscripts 
Extended characterization of the novel co-isogenic C57BL/6J Prnp ${ }^{-/-}$mouse line Mario Nuvolone ${ }^{1}$, Silvia Sorce ${ }^{1}$, Marta Paolucci ${ }^{1}$ and Adriano Aguzzi ${ }^{1}$. ${ }^{1}$ Institute of Neuropathology, University Hospital of Zurich, Zurich, Switzerland

Address for correspondence: Adriano Aguzzi, Institute of Neuropathology, University Hospital of Zurich, Zurich, Switzerland. Email: adriano.aguzzi@usz.ch

Background. Besides its involvement in peripheral myelin maintenance, the physiologic function of the ubiquitously expressed cellular prion protein $\operatorname{PrP}^{\mathrm{C}}$ remains enigmatic. Phenotypic studies on previously available Prnp $^{-/-}$mouse lines, produced in 129-derived embryonic stem cells and backcrossed to non-129 strains, were systematically confounded by Prnp-linked loci polymorphic between 129 and the backcrossing strain and have led to erroneous conclusions [1]. We have recently applied genome-editing to generate a novel coisogenic Prnp $^{-/}$mouse line (termed ZH3 line) in the well characterized C57BL/6J background [2]. Genetic and phenotypic characterization of this line excluded the presence of artefactual phenotypes reported in non-co-isogenic $P_{r n p}{ }^{-/-}$mouse lines and confirmed the crucial involvement of $\mathrm{PrP}^{\mathrm{C}}$ in peripheral myelin maintenance through the interaction with Gpr126 $[2,3]$. Here, we aimed at extending the characterization of the Prnp ${ }^{\mathrm{ZH} 3 / \mathrm{ZH} 3}$ mouse line.

Materials and methods. Data on single nucleotide polymorphism (SNPs) informative among different C57BL/6 substrains were extrapolated from a whole-genome SNP analysis performed as previously described [2]. Genotyping protocols to investigate the presence of mutations/deletions in Crbl, Snca/Mmrnl and Nnt were as previously described [4, 5, 6]. Prion inoculations and relative analyses were all performed as previously described [7].

Results. Since its establishment, the C57BL/6 inbred strain has led to the origin of several substrains, which differ genetically and phenotypically with respect to the reference C57BL/6J [8]. To verify the genetic makeup of the Prnp ${ }^{\mathrm{ZH} 3 / \mathrm{ZH} 3}$ mouse line, we analyzed 12 SNPs known to be informative among different C57BL/6 substrains. The Prnp ${ }^{\mathrm{ZH} 3 / \mathrm{ZH} 3}$ line showed an allelotype identical to the C57BL/6J reference strain (Figure 1A). We next investigated the $\operatorname{Prnp}^{\mathrm{ZH} 3 / \mathrm{ZH} 3}$ line for the presence of specific deletions or mutations reported in different C57BL/6 substrains using established genotyping assays. The Prnp ${ }^{\mathrm{ZH} 3 / \mathrm{ZH} 3}$ line showed the presence of the partial deletion of $N n t$, described in the C57BL/6J reference strain [6], but not of the Rd8 mutation of the Crbl gene, described in the C57BL/6N strain [4], nor the deletion of Snca/Mmrn1, reported in the C57BL/6JOlaHsd strain [5] (Figure 1A). Collectively, these data confirmed that the $\operatorname{Prnp}^{\mathrm{ZH} 3 / \mathrm{ZH} 3}$ line is indistinguishable with respect to the C57BL/6J reference strain in all investigated genomic loci.

Expression of membrane-bound $\mathrm{PrP}^{\mathrm{C}}$ is necessary to sustain the replication and neurotoxicity of prions and mice devoid of $\operatorname{PrP}^{\mathrm{C}}$ resist prion infection. To verify prion resistance of the novel knockout line, we intracerebrally inoculated $\operatorname{Prnp}^{\mathrm{ZH} 3 / \mathrm{ZH} 3}$ and C57BL/6J wild-type mice with the $22 \mathrm{~L}$ prion strain or with non-infectious brain homogenate (NBH) as control. Only 22L-inoculated C57BL/6J wild-type mice developed typical signs of scrapie and achieved the terminal stage of the disease with a median incubation of 141 days post-injection. Conversely, NBH-injected C57BL/6J wild-type mice and both 22L- and NBH-injected $\operatorname{Prnp}^{\mathrm{ZH} 3 / \mathrm{ZH} 3}$ mice showed no clinical signs of scrapie and survived more than 200 days (Figure 1B). Histological 
analysis confirmed the presence of spongiosis and accumulation of the partially-protease resistant prion protein, typical hallmarks of prion disease, only in 22L-inoculated C57BL/6J wild-type mice and not in any other experimental group. Altogether, these data confirmed the prion resistance of the Prnp ${ }^{\mathrm{ZH} 3 / \mathrm{ZH} 3}$ mouse line.

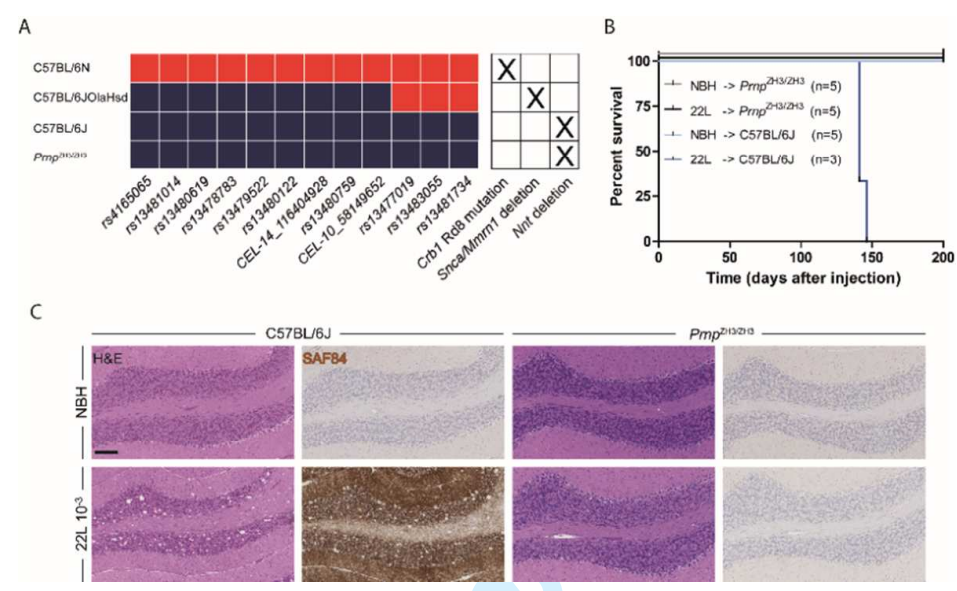

Figure 1. A. SNP and mutation analysis of Prnp ${ }^{\mathrm{ZH} 3 / \mathrm{ZH} 3}$ mice and reference $\mathrm{C} 57 \mathrm{BL} / 6$ substrains. $\mathrm{X}$ denotes presence of a specific mutation/deletion. B. Survival after injection with prions (22L) or control $(\mathrm{NBH})$. $\mathrm{n}$ denotes the number of mice in each group. C. Histologic analysis of cerebelli of representative mice from B. SAF84 shows partially protease resistant prion protein. Scale bar: $100 \mu \mathrm{m}$.

Discussion and conclusions. This study confirms the co-isogenicity of the $\operatorname{Prnp}^{\mathrm{ZH} 3 / \mathrm{ZH} 3}$ line with the C57BL/6J reference strain and its resistance to prion infection. Together with the extensive genomic, transcriptomic and phenotypic characterization reported $[2,3]$, this study corroborates the notion the $\operatorname{Prnp}^{\mathrm{ZH} 3 / \mathrm{ZH} 3}$ line is a rigorous genetic resource for investigating the role of $\operatorname{PrP}^{\mathrm{C}}$ in physiology and disease.

Declaration of interest. The authors have no conflict of interest to report.

References. 1. Nuvolone M, Kana V, Hutter G, Sakata D, Mortin-Toth SM, Russo G, et al. SIRPalpha polymorphisms, but not the prion protein, control phagocytosis of apoptotic cells. J Exp Med. 2013;210:2539-52.

2. Nuvolone M, Hermann M, Sorce S, Russo G, Tiberi C, Schwarz P, et al. Strictly coisogenic C57BL/6J-Prnp-/- mice: A rigorous resource for prion science. J Exp Med. 2016;213:313-27.

3. Kuffer A, Lakkaraju AK, Mogha A, Petersen SC, Airich K, Doucerain C, et al. The prion protein is an agonistic ligand of the $G$ protein-coupled receptor Adgrg6. Nature. 2016;536:464-8.

4. Mattapallil MJ, Wawrousek EF, Chan CC, Zhao H, Roychoudhury J, Ferguson TA, et al. The $\mathrm{Rd} 8$ mutation of the Crb1 gene is present in vendor lines of C57BL/6N mice and embryonic stem cells, and confounds ocular induced mutant phenotypes. Invest Ophthalmol Vis Sci. 2012;53:2921-7.

5. Specht CG, Schoepfer R. Deletion of multimerin-1 in alpha-synuclein-deficient mice. Genomics. 2004;83:1176-8.

6. Huang TT, Naeemuddin M, Elchuri S, Yamaguchi M, Kozy HM, Carlson EJ, et al. Genetic modifiers of the phenotype of mice deficient in mitochondrial superoxide dismutase. Hum Mol Genet. 2006;15:1187-94.

7. Sorce S, Nuvolone M, Keller A, Falsig J, Varol A, Schwarz P, et al. The role of the NADPH oxidase NOX2 in prion pathogenesis. PLoS Pathog. 2014; 10:e1004531.

8. Zurita E, Chagoyen M, Cantero M, Alonso R, Gonzalez-Neira A, Lopez-Jimenez A, et al. Genetic polymorphisms among C57BL/6 mouse inbred strains. Transgenic Res. 2011;20:4819. 